\title{
The Acoustic Analysis of Kazak Vowel /e/
}

\author{
Xin Rui-qing \\ Key Lab of China's National Linguistic Information Technology, \\ Northwest Minzu University, Lanzhou 730030, China \\ ruiqingxin@163.com
}

Key words: Vowel /e/ in Kazak, monphthong, diphthong

\begin{abstract}
Phonetic experiments with Kazak words including vowel /e/ in different positions were undertaken, and formant values of the onset point and the offset point of the sounding process of each /e/ have been extracted and analyzed. The results and finding indicate that vowel /e/ in Kazak is not a diphthong but a monphthong.
\end{abstract}

\section{Introduction}

There are 9 vowels in Kazak /a/, /æ/, /e/, /o/, /ø/, /u/, /y/, /ə/ and /it/ (Here, the IPA are cited from $A$ Course of Acoustic Phonetics[1] and Modern Kazak Practical Grammar[2].). Generally, the 9 vowels are divided into two groups according to the tongue positions in pronouncing, that is front vowels/æ/, /e/, /ø/, /y/, /í/ and back vowels /a/, /o/, /u/, /ð/. "At present, all the 9 vowels are recognized as monophthongs in the research field of Kazak in China, while vowels /e/ and /o/ are demonstrated to be diphthongs by the current research results in Kazakhstan"[3]. Besides, based on an acoustic analysis of vowel /i/ (Here /i/ is the same as / $\mathbf{i} /$.) and a comparison of tongue positions of the Kazak vowel with its possible counterparts in the cardinal vowel pattern, Zheng Huan has demonstrated that "Kazak vowel /i/ is actually not the vowel [i] (front high vowel), [i] (central high

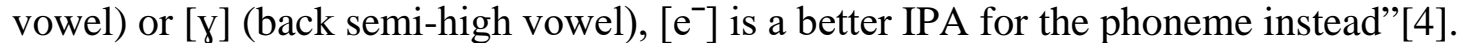

Obviously, there are still disputes in Kazak vowel system, and this is why in this paper, the phonetic marker "/ /" is used instead of "[ ]". "/ /" is the marker for broad transcription, in which the phonetic symbol is a phoneme, standing for a series of possible allophones, while "[ ]" is the marker for narrow transcription in which the phonetic symbol stands for the exact pronunciation of a certain sound[5]. Kazak vowel /e/ is recognized as a front high monophthong by most researchers in China but is believed be to a diphthong in Kazakhstan, while in China's research it also has been reported that when /e/ is the first letter of a word, $/ \mathrm{j} /$ is often added before it in pronouncing[6]. Therefore, more researches are needed to solve the dispute. This paper centers on the properties of Kazak vowel /e/ by means of acoustic analysis.

\section{Research Design}

To monophthongs, the tamber is decided by the first three formants, among which the first two formants F1 and F2 are especially sensitive to the changes of lips and tongue positions, thereafter, the values of F1 and F2 are usually taken as the main elements in vowel depiction[7]. Comparatively speaking, each monophthong has a stable and unique formant pattern. In diphthong pronouncing, a process of sliding from one phoneme to another one can be perceived. Lips and tongue positions change with the sliding between the two phonemes, leaving an unequivalent distribution of stress and strength between the two phonemes[8]. Most important, there must be two apparent formant patterns in the acoustic properties of a diphthong. Therefore, with the help of formant pattern and comparison of formant values, whether a vowel is a monophthong or a diphthong can be testified.

\subsection{Words for Pronouncing}

In order to guarantee all possible positions of /e/ in words, and all possible influences of consonants to the pronunciation of /e/, 200 Kazak words involving all six syllable types (v, vc, vcc, cv, cvc, cvcc) were filtered. The syllable numbers of the words were ranged from 1 to 4 , and the letters before and after /e/ covered all the 22 consonants of Kazak (Consonants /f/ and /v/ are only used in 
borrowed words, and borrowed words are not included in this research for certain reason.) The sample of the word list for pronouncing is in figure 1.

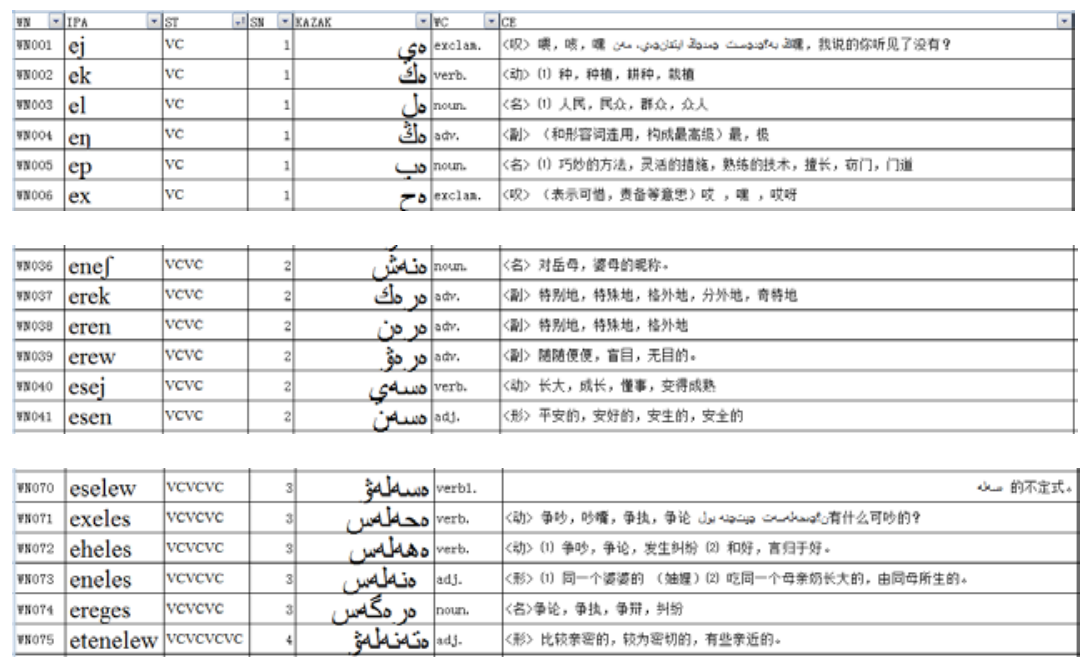

Fig. 1 Samples of world list for pronouncing

※ WN=world number, IPA= International Phonetic Alphabet, ST=syllable type, $\mathrm{SN}=$ syllable number, $\mathrm{WC}=$ word class, $\mathrm{CE}=$ Chinese equivalents

\subsection{Subjects}

To testify whether the Kazak vowel /e/ is a monophthong or a diphthong, only the comparison of formant patterns and formant values of the onset part and the offset part of the vowel's sounding process is required. Thus, the difference in formant values between males and females can be neglected. Furthermore, because of the physical features of females, the resonance is relatively weak in their pronouncing, so it is often difficult to extract data from females' sound signals. Therefore, only 4 male subjects were invited in the research. All of them are at the age between 18 to 22 and from different counties in Xinjiang Province, which are in the area of north-east dialect.

\subsection{Data Collection}

The phonetic signals were recoded at the studio with the software Audition 3.0 (Chinese version) and the equipments of a laptop computer, an external sound card of Yamaha Steinberg UR242 with USB Audio Interface, and a Sony Omni directional microphone. Signals were collected at the sampling rate of $16000 \mathrm{~Hz}, 16$-bit, single track and saved as Microsoft .wav file.

The signals were then cut into separate and named according to the sequence of the subjects and the words. For example, M1001 is the file name of the sound of the first word pronounced by the first male, so on and so forth. Praat was used for the analysis and formants collection as that in figure 2.

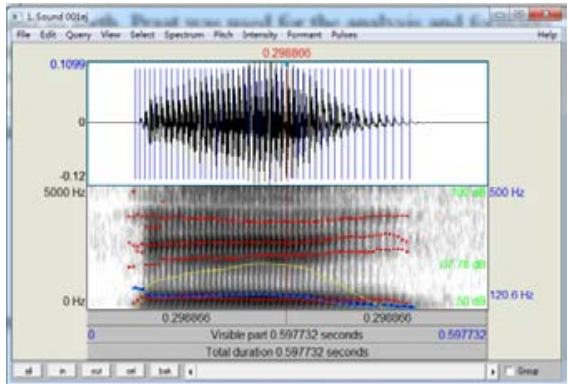

Fig. 2 Sample of wideband spectrum of KZK word /ej/(ب)

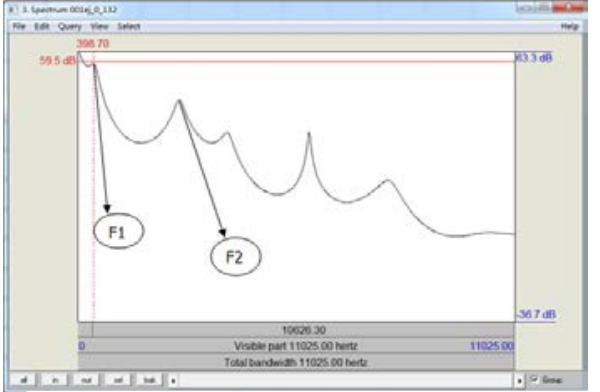

Fig. 3 Sample of formant analysis by LPC 
Because the formant values extracted by Praat automatically are not always exact, LPC analysis was taken to get the formant values of the front part and the back part of the vowel's sounding process. One point on the front part and the back part of each vowel /e/ was extracted respectively for LPC analysis. The sampling rate of the signals was set at $16000 \mathrm{~Hz}$, so the prediction order was set at 16 in LPC analysis[9]. The sample of formant values by LPC analysis is as that in figure 3. If the first two formants are not typical (This phenomenon is common to F1.) in the condition of prediction order $=16$, then the prediction order is set at 20 , and the formant distribution in this condition can be taken as a reference merely, like that in figure 4 .

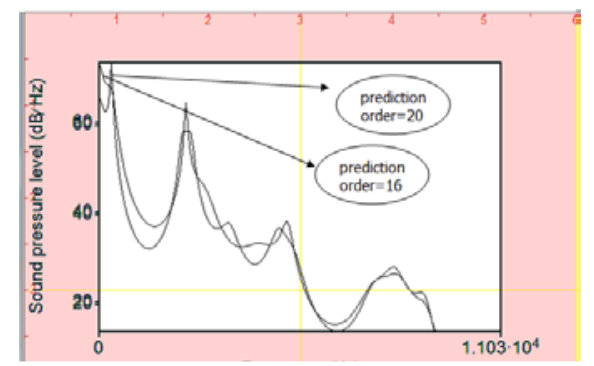

Fig. 4 The formant distributions in different prediction orders

\section{Results Analysis and Findings}

The formant values extracted from LPC were put into Excel for detailed analysis.

\subsection{Properties of Vowel /e/ as the Initial}

Data in table 1 are formant values of vowel /e/ as the initial letter of the words. The data indicate that there is not a great difference between the formant values of onset point and offset point, no matter in the term of F1 or F2. Therefore, vowel /e/ has no apparent properties of a diphthong, and this can also be demonstrated by the vowels' relative tongue position in figure 5 . The distribution of most vowels in figure 5 is centered on one point, and only three vowels scatter away from the point, which contribute a little to the differentiation of the vowels.

Table 1. Formant values of vowel /e/

\begin{tabular}{|c|c|c|c|c|c|}
\hline \multirow[t]{2}{*}{ IPA } & \multirow[t]{2}{*}{ KZK } & \multicolumn{2}{|c|}{ onset point } & \multicolumn{2}{|c|}{ offset point } \\
\hline & & F1 & F2 & F1 & F2 \\
\hline ej & هي & 399 & 2557 & 382 & 2541 \\
\hline ek & & & 2557 & 431 & 2458 \\
\hline$C$ & & & 2508 & 449 & 2557 \\
\hline ey & مأ & 99 & 2541 & 423 & 2151 \\
\hline ер & هُ & 82 & 2491 & 465 & 2474 \\
\hline ex & $\tau^{\circ}$ & & 2258 & 465 & 2474 \\
\hline es & مش مش & 66 & 2557 & 465 & 2491 \\
\hline ez & jo & 83 & 2392 & 449 & 2474 \\
\hline em & مم & 366 & 2507 & 399 & 2507 \\
\hline en & من & 432 & 2441 & 415 & 2474 \\
\hline er & ر & & 2474 & 465 & 2408 \\
\hline es & س l l l l & & 2524 & 449 & 2606 \\
\hline et & هت & 332 & 2541 & 432 & 2458 \\
\hline
\end{tabular}

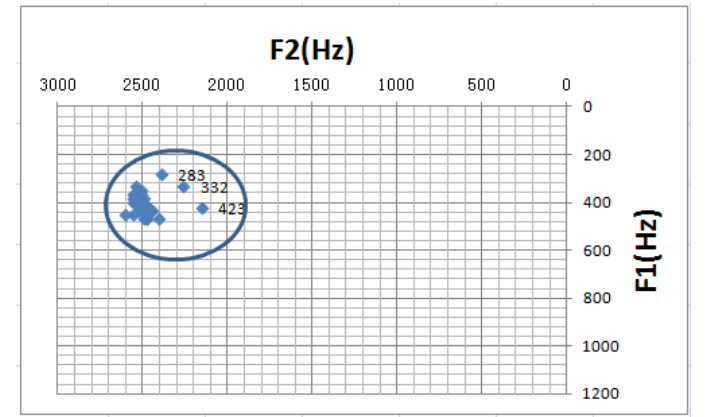

Fig. 5 Distribution of vowel /e/ as initials

However, in auditory perception, an obvious /i/ or / j/ can be recognized before the vowel /e/, and evidence can be drawn from the wideband spectrum of some words, such as that in figure 6 . Both of the wideband spectrums in figure 6 show that there is a short bending part on F1 and F2 at the beginning of the sounding process, which only takes up no more than 0.04 second. This can be taken as the phonetic property reflected in the transition from a consonant to a vowel, but not the 
property reflected in the sliding process from one vowel phoneme to another in a diphthong like what is displayed in figure 7. In a diphthong, both of the two phonemes take up a relatively long time although one is shorter and the other one is longer according to the stress allocation between them. For example, in figure 7 the wideband spectrum of diphthong /ia/ indicates the phoneme /i/ takes about 0.188 second, while the phoneme /a/ takes a little more time, because diphthong /ia/ in Monguor language is a back stress one.

Therefore, the phoneme before vowel /e/ perceived in audition should not be vowel [i], but be the semi-vowel [j] instead, and it can be believed Kazak vowel /e/ as initials is not a diphthong, but should be a monophthong [e].

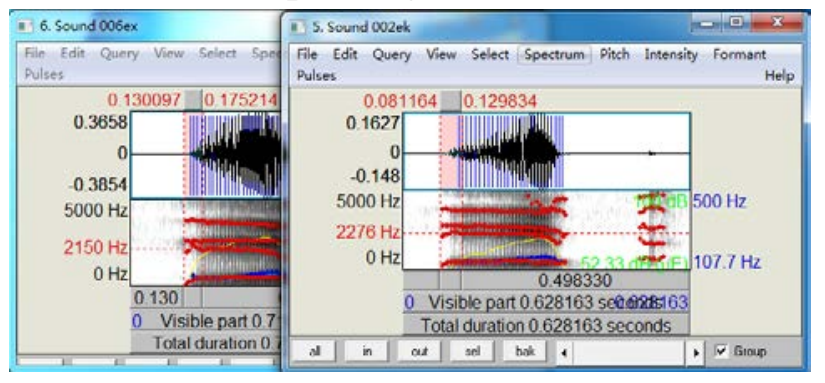

Fig. 6 Sample of wideband spectrum of words /ek/ and /ex/

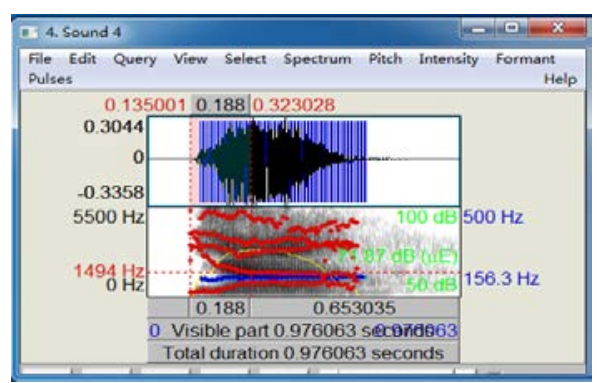

Fig. 7 Sample of wideband spectrum of diphthong /ia/ in Monguor language

\subsection{Properties of Vowel /e/ in the Middle and End Positions}

Data in table 2 are formant values of vowel /e/ in the middle and end positions of the words. The data indicate that there is either no great difference between the formant values of onset point and offset point both in terms of F1 and F2. Therefore, vowel /e/ in the middle and end positions show properties of an exact monophthong and this has been demonstrated by the vowels' relative tongue position in figure 8 . The distribution of all vowels in figure 8 is centered in one area, and no obvious border of groups can be recognized.

Table 2. Formant values of some vowel /e/ in the middle and end positions

\begin{tabular}{|c|c|c|c|c|c|}
\hline \multirow[t]{2}{*}{ IPA } & \multirow[t]{2}{*}{ KZK } & \multicolumn{2}{|c|}{ onset point } & \multicolumn{2}{|c|}{ offset point } \\
\hline & & F1 & F2 & F1 & F2 \\
\hline ebe & هبه & 399 & 2524 & 432 & 2574 \\
\hline ege & مكه & 349 & 2328 & 365 & 2328 \\
\hline ese & مسه & 365 & 2500 & 400 & 2500 \\
\hline ele & مله & 400 & 2467 & 400 & 2190 \\
\hline ene & منه & 400 & 2431 & 400 & 2397 \\
\hline ebep & مبحٍ & 365 & 2362 & 434 & 2328 \\
\hline egej & مكابي & 331 & 2259 & 365 & 2293 \\
\hline eken & مكمن & 434 & 2431 & 400 & 2156 \\
\hline ekew $^{a}$ & مكهة & 365 & 2224 & 400 & 2086 \\
\hline eke & مكشش & 400 & 2328 & 434 & 2259 \\
\hline
\end{tabular}

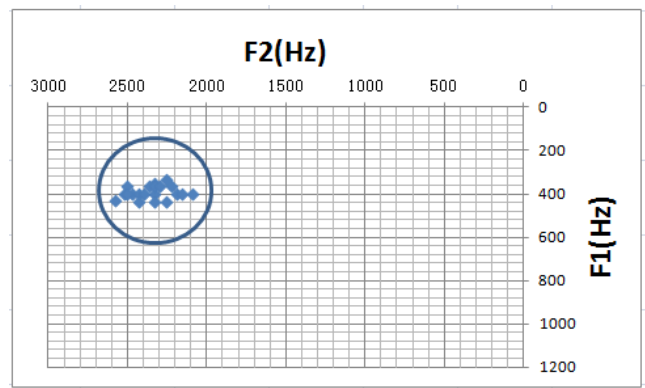

Fig. 8 Distribution of vowel /e/ in the middle and end positions

It is indicated in figure 8 that there is a limited scattering distribution in horizon (F2), and this is to some extent affected by the assimilation of the consonants before and/or after the vowel. A typical case of assimilation ekew ${ }^{\mathrm{a}}$ (o) is in table 2. The formant values of the offset point of the second vowel /e/ is $400 \mathrm{~Hz}$ (F1) and $2086 \mathrm{~Hz}$ (F2), which is much lower than the common values of F2 in other words. F2 is degraded by the assimilation of the semi-vowel /w/, which is shown in figure 9 . 


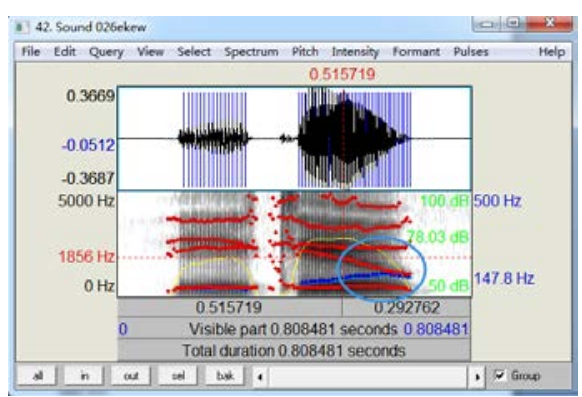

Figure 9. The sample of wideband spectrum of ekew ${ }^{\mathrm{a}}($ o $)$

\section{Summary}

The above results analysis and findings of the phonetic experiment have offered fundamental evidences to the conclusion that Kazak vowel /e/ is not a diphthong but a monophthong, although the semi-vowel $/ \mathrm{j} /$ is often added before it, especially when /e/ is in the initial.

However, to get the most exact properties of vowel /e/ in Kazak, more researches and evidences are always necessary and not enough.

\section{Acknowledgments}

This paper is based on part of the research findings of Northwest Minzu University Graduate Innovation Project The Acoustic Properties of Kazak Consonants (Project No.: YXM2016002).

\section{References}

[1] Gong Shimin \& Li Zengxiang. An Introduction to Kazak[M]. Beijing: The Ethnic Publishing House, 1985.

[2] Zhang Dingjing. Modern Kazak Practical Grammar[M]. Beijing: China Minzu University Press , 2004.

[3] Zhou Yan. The Analysis of Kazak Vowel System[D]. Graduate thesis of China Minzu University, 2014.

[4] Zheng Huan, The Acoustic Analysis of Kazak Vowel i[J]. Journal of Yili Normal University (Social Science Edition), 2009 (12): 13-17.

[5] Wang Yuanxin. A Course of Linguistics[M]. Beijing: China Minzu University Press, 2014: 68.

[6] Gong Shimin \& Li Zengxiang. An Introduction to Kazak[M]. Beijing: The Ethnic Publishing House, 1985: 4.

[7] Bao Huaiqiao \& Lin Maocan. Essentials of Experimental Phonetics[M]. Beijing: Peking University Press, 2014: 102.

[8] Bao Huaiqiao \& Lin Maocan. Essentials of Experimental Phonetics[M]. Beijing: Peking University Press, 2014: 116.

[9] Xiong Ziyu. Handbook for Praat[Z]. http://www.praat.org, 2004: 76. 